\title{
Vitelline envelope genes of the yellow fever mosquito, Aedes aegypti
}

\author{
Marten J. Edwards ${ }^{a, *}$, David W. Severson ${ }^{b}$, Henry H. Hagedorn ${ }^{c}$ \\ ${ }^{a}$ Department of Genetics, Case Western Reserve University, Cleveland, OH 44106 USA \\ ${ }^{\mathrm{b}}$ Department of Biological Sciences, University of Notre Dame, Notre Dame, IN 46556, USA \\ ${ }^{c}$ Department of Entomology and Center for Insect Science, University of Arizona, Tucson, AZ 85721 USA
}

Received 16 March 1997; received in revised form 29 July 1998; accepted 17 August 1998

\begin{abstract}
Vitelline envelope genes from the mosquito Aedes aegypti were analyzed with respect to their DNA sequences, genomic representation, temporal and spatial expression profiles and response to 20-hydroxyecdysone. Genomic clones of three vitelline envelope genes, 15a-1, 15a-2 and 15a-3 were isolated. Southern analysis indicates that all three genes are represented by a single copy in the genome. The deduced amino acid sequences of all three vitelline envelope genes contain a conserved region of 46 residues that overlaps with a region that is conserved in four Drosophila melanogaster vitelline envelope genes. DNA was sequenced flanking the $15 \mathrm{a}-1,15 \mathrm{a}-2$ and $15 \mathrm{a}-3$ coding regions. A 360 bp sequence $5^{\prime}$ of the $15 \mathrm{a}-2$ coding region was identified with $72 \%$ identity to a sequence upstream of the Ae. aegypti VgA1 vitellogenin gene. The temporal patterns of 15a-1, 15a-2 and 15a-3 expression, as determined by Northern analysis, were similar. The spatial patterns of expression, as determined by whole-mount in situ hybridization, differed between the three genes. $15 \mathrm{a}-1$ and $15 \mathrm{a}-3$ were only expressed in the middle and posterior regions of the follicle, while 15a-2 was also expressed at the anterior region. Vitelline envelope gene expression was higher in ovaries that were dissected at 0,2 and $10 \mathrm{~h}$ following a blood meal and then incubated in vitro for $10 \mathrm{~h}$ in medium containing $10^{-5} \mathrm{M} 20$-hydroxyecdysone, compared to ovaries that were incubated without hormone. (c) 1998 Elsevier Science Ltd. All rights reserved.
\end{abstract}

Keywords: Aedes aegypti; Vitelline envelope; 20-hydroxyecdysone

\section{Introduction}

Eggshell development in the yellow fever mosquito, Aedes aegypti, provides a model system for investigating the physiological regulation of gene expression. To make an eggshell, several proteins are secreted in an ordered spatial and temporal pattern by the follicular epithelium (Regier and Kafatos, 1985). The vitelline envelope (membrane) is the innermost layer of the eggshell. The formation and ultrastructure of the Ae. aegypti vitelline envelope has been studied by Anderson and Spielman (1971, 1973), Mathew and Rai (1975), Powell et al. (1988) and Raikhel and Lea $(1982,1991)$ and reviewed by Edwards (1996). The vitelline envelope is formed by the coalescence of protein droplets (plaques) which are secreted by the follicular epithelium.

\footnotetext{
* Corresponding author. Fax (216) 368-3432; e-mail
} mje8@po.cwru.edu
Vitelline envelope proteins are secreted during a period of elevated 20-hydroxyecdysone titer following a blood meal (Hagedorn et al., 1975; Greenplate et al., 1985; Racioppi et al., 1986, Lin et al., 1993). 20-hydroxyecdysone is involved in the coordinated development of eggs from a resting stage to maturity within 3 days. This hormone has been shown to influence the development of the vitelline envelope by Raikhel and Lea (1982, 1991). Vitelline envelope gene expression was shown to respond to 20-hydroxyecdysone in vitro by Lin et al. (1993). In this study, we investigated further the effect of 20-hydroxyecdysone on vitelline envelope gene expression in vitro.

An Ae. aegypti vitelline envelope gene (15a-1) was cloned by differentially screening a genomic library with cDNA prepared from blood-fed and non-blood-fed mosquitoes, respectively (Gemmill et al., 1986). Subsequently, a 15a-1 cDNA clone and a partial cDNA clone of a second Ae. aegypti vitelline envelope gene (15a-2) were isolated by Lin et al. (1993). Southern 
analysis indicated that a single copy of the $15 \mathrm{a}-1$ gene is present in the genome.

Sequence similarity was detected between $15 \mathrm{a}-1,15 \mathrm{a}-$ 2 and four vitelline envelope genes that had been previously cloned from D. melanogaster (Lin et al., 1993). Sequences upstream of the coding regions of two $D$. melanogaster vitelline envelope genes were reported by Scherer et al. (1993) and by Gargiulo et al. (1991). The regulation of $D$. melanogaster vitelline envelope genes has been studied by Savant and Waring (1989), Scherer et al. (1993), Jin and Petri (1993) and Cavaliere et al. (1997).

Through a comparative analysis of vitelline envelope gene sequences, we predicted that cis-acting DNA elements may be revealed. To this end, genomic clones were isolated for 15a-1, 15a-2, and for a third member (15a-3) of the Ae. aegypti vitelline envelope gene family. Restriction fragments of these clones containing the transcriptional units and flanking DNA were sequenced and compared with each other and to the D. melanogaster vitelline envelope gene sequences. The response of the vitelline envelope genes to 20-hydroxyecdysone, and their temporal and spatial patterns of expression, are also examined.

\section{Methods}

\subsection{Animals}

The Rockefeller strain of Ae. aegypti was used in all of the experiments except for RFLP analysis. These mosquitoes were reared as described by Shapiro and Hagedorn (1982). Adult females were fed 4 days after eclosion on warmed cow blood supplemented with $2 \mathrm{mg} / \mathrm{ml}$ isoleucine and $1 \mathrm{mM}$ ATP through a stretched Parafilm membrane. For RFLP analysis, Ae. aegypti mosquitoes were reared as described by Christensen and Sutherland (1984).

\subsection{Chemicals and cloning vectors}

DNA modifying enzymes, nucleotides, digoxigenin11 dUTP and proteinase $\mathrm{K}$ were from BoehringerMannheim Biochemicals (Indianapolis, IN). Taq polymerase was from BRL Life Technologies (Gaithersburg, MD). $\alpha{ }^{-32} \mathrm{P}$ dCTP $(3000 \mathrm{Ci} / \mathrm{mmol})$ was from New England Nuclear (Boston, MA). Paraformaldehyde and formaldehyde were from Polysciences (Warrington, PA). 20-hydroxyecdysone was from Sigma (St Louis, MO). pBluescript cloning vector was from Stratagene (La Jolla, CA).

\subsection{Genomic library screening}

Construction of the EMBL3 (Stratagene) Rockefeller strain Ae. aegypti genomic library was described by Bar-
illas-Mury and Wells (1993). The Rockefeller strain Ae. aegypti genomic library in the vector Lambda-DASH (Stratagene) was kindly provided by Dr Anthony James (University of California, Irvine). Hybridization probes corresponding to the $15 \mathrm{a}-1$ and $15 \mathrm{a}-2$ coding regions were labeled with $\alpha-{ }^{32} \mathrm{P} \mathrm{dCTP}$ or digoxigenin-11 dUTP using random primers (Feinberg and Vogelstein, 1983). Screening and plaque purification procedures were performed as described by Sambrook et al. (1989).

\subsection{DNA sequencing}

Restriction fragments of genomic clones were subcloned into pBluescript II $\mathrm{KS}^{-}$vector (Stratagene). Sequencing primers were T3, T7 (Stratagene) and several synthetic oligonucleotides that were prepared at the University of Arizona Division of Biotechnology (Tucson, AZ). Sequence was obtained using an automatic DNA sequencer (Model 373A, Applied Biosystems Int., Forster City, CA) at the University of Arizona Division of Biotechnology and the Molecular Genetics Instrumentation Facility at the University of Georgia (Athens, GA). Complete and overlapping sequences were obtained for each strand. Thus, all sequences were verified by at least one sequencing reaction in the opposite direction. The sequence data were analyzed using the "Sequence Analysis Software Package" version 7.1 from the Genetics Computer Group (Devereaux et al., 1984). GCG programs used included Pileup for multiple sequence alignment and GAP PILEUP for sequence comparisons and BLAST for database searches.

\subsection{Hybridization probes}

For whole-mount in situ hybridization experiments, mutually exclusive probes were constructed using the polymerase chain reaction (PCR). Antisense ( $3^{\prime}-$ to $5^{\prime}$ orientation) and sense $\left(5^{\prime}-\right.$ to $3^{\prime}$-orientation) primers flanked the predicted $3^{\prime}$-untranslated regions of the transcriptional units, respectively. Using restriction fragments containing the $3^{\prime}$-untranslated regions as templates, 200, 160 and $130 \mathrm{nt}$ single stranded probes were generated. PCR reactions were carried out in a Coy Model 50 TempCycler (Ann Arbor, MI). The reaction mixtures contained 1X PCR buffer (Life Technologies), $1.6 \mathrm{mM} \mathrm{MgCl}_{2}, 0.1 \mathrm{mM}$ dATP, dCTP and dGTP, $0.035 \mathrm{mM}$ dTTP and $0.065 \mathrm{mM}$ digoxigenin-11 dUTP, $150 \mathrm{ng}$ of a single primer and 1.25 units of Taq polymerase. Probe concentration was estimated by colorometric detection in comparison to digoxigenin-labeled control DNA (Boehringer Mannheim).

For mutually exclusive Northern and Southern analysis, radiolabeled hybridization probes were prepared by extension from antisense primers. Reactions were performed using $\alpha-{ }^{32} \mathrm{P}$ dCTP and the Klenow fragment of 
DNA polymerase I. For Northern blot analysis of the effect of 20-hydroxyecdysone on ovaries cultured in vitro, a 350 bp restriction fragment of the $15 \mathrm{a}-1$ coding region was labeled with $\alpha{ }^{-32} \mathrm{P}$ dCTP using the random primer method (Feinberg and Vogelstein, 1983).

\subsection{RNA isolation and characterization}

Ovaries were dissected from female mosquitoes at intervals following a blood meal. Development of ovaries was determined by measuring yolk length using an ocular micrometer on a dissecting microscope. Yolk lengths were compared to published data of Yonge and Hagedorn (1977) and Raikhel and Lea (1991). Total RNA was prepared from dissected ovaries using an RNaid RNA purification kit (Bio 101, Vista, CA) with modifications of Noriega and Wells (1993). For temporal expression profiles, $4 \mu \mathrm{g}$ of total RNA were loaded per lane. For in vitro culture experiments, $12 \mu \mathrm{g}$ of total RNA were loaded per lane for all time points except for the 36-h time point, in which $1.2 \mu \mathrm{g}$ were loaded. Relative RNA loading was estimated using an Aedes albopictus 18S ribosomal RNA probe (18S RNA), provided by Dr Ann M. Fallon (University of Minnesota, St Paul).

Total RNA was separated on a $1.5 \%$ agarose gel containing $10 \%$ formaldehyde and transferred to a charged nylon membrane. Hybridizations were performed at $65^{\circ} \mathrm{C}$ in $5 \mathrm{X}$ SSPE, 5X Denhard's solution, $0.1 \mathrm{mg} / \mathrm{ml}$ sheared salmon sperm and $0.1 \%$ SDS. The amount of radioactivity bound to individual samples on the nylon membrane was determined using a Betascope (Betagene, Waltham, MA). Bound radioactivity was removed by several washes in $5 \%$ SDS at $100^{\circ} \mathrm{C}$. The effectiveness of the removal was determined using the Betascope.

\subsection{Southern blot and RFLP linkage analysis}

DNA was isolated from adult mosquitoes according to the methods of Severson (1997). EcoRI-digested DNA from single mosquitoes was size fractionated on $0.9 \%$ agarose gels, photonicked by UV exposure, denatured (150 mM NaOH, $3 \mathrm{mM}$ EDTA), neutralized (150 mM $\mathrm{NaPO}_{4}, \mathrm{pH}$ 7.8), and transferred to Gene Screen Plus (New England Nuclear) by capillary action in $25 \mathrm{mM}$ $\mathrm{Na}_{4} \mathrm{P}_{2} \mathrm{O}_{7}$. Hybridizations and washes were performed at $65^{\circ} \mathrm{C}$. Filters were washed twice in $2 \mathrm{X}$ SSC with $0.1 \%$ SDS for 15 min and twice on $0.2 \mathrm{X}$ SSC with $0.1 \%$ SDS for $15 \mathrm{~min}$ then exposed to Kodak XAR film for 14 days at $-70^{\circ} \mathrm{C}$ with an intensifying screen.

RFLP genetic data for 15a-1, 15a-2 and 15a-3 are based on three separate Ae. aegypti $\mathrm{F}_{2}$ backcross populations of the following pairwise matings: (Formosus strain by RED strain), ( $F_{1}$ backcrossed to RED strain). The RED strain is homozygous for mutant marker genes for each of the three Ae. aegypti chromosomes including, red-eye on chromosome 1, spot abdomen on chromo- some 2, and black tarsus on chromosome 3. Two point recombination values were determined using the MAPMAKER computer program (Lander et al., 1987). A LOD threshold of 3.0 was used to detect linkage between loci.

\subsection{Whole-mount in situ hybridization}

Ovaries were dissected from mosquitoes $24 \mathrm{~h}$ following a blood meal and fixed overnight in freshly prepared $4 \%$ paraformaldeyde in $1 \mathrm{X}$ PBS containing $0.1 \%$ Tween-20 (PBT). Ovaries were dehydrated through a methanol-PBT series $(25 \%, 50 \%$ and $75 \%$ methanol in PBT and $100 \%$ methanol) and transferred to $100 \%$ ethanol for storage at $-20^{\circ} \mathrm{C}$. Ovaries were cleared in $100 \%$ xylene for $2 \mathrm{~h}$ after passage through a series of washes in $25 \%$ and $50 \%$ xylene in ethanol. Xylene treatment was followed by washes in $50 \%$ xylene in ethanol and finally $100 \%$ ethanol. Ovaries were rehydrated through a methanol-PBT with 5\% formaldehyde series, and rinsed in PBT. Ovaries were permeablized by treatment for $30 \mathrm{~min}$ in PBT plus $50 \mathrm{mg} / \mathrm{ml}$ proteinase K. Protease treatment was stopped by washing with PBT plus $2 \mathrm{mg} / \mathrm{ml}$ glycine. Post-fixation was performed in 5\% formaldehyde in PBT.

Ovaries to be used in a single experiment were fixed, cleared and permeablized with proteinase $\mathrm{K}$ together in order to reduce variations in background and signal intensity. Subsequently, the ovaries were divided into groups and hybridized separately with digoxigenin-labeled mutually exclusive probes. Hybridization, washing and detection steps were performed according to the methods of Tautz and Pfeifle (1989). Following color development, ovaries were mounted in $50 \%$ glycerol containing $10 \mathrm{mM}$ Tris $\mathrm{pH} 7.4$ and $1 \mathrm{mM}$ EDTA.

\subsection{In vitro culture of ovaries}

Ten pairs of ovaries were dissected from mosquitoes at intervals $(0,2,10$ and $36 \mathrm{~h})$ after a blood meal. Mosquitoes at $0 \mathrm{~h}$ were collected as they finished feeding. Ovaries were cultured for $10 \mathrm{~h}$ at $26^{\circ} \mathrm{C}$ in a complex medium formulated for Ae. aegypti organ culture (Bohm et al., 1978). For 20-hydroxyecdysone treatments, the culture medium was brought to a final concentration of $10^{-5} \mathrm{M} 20$-hydroxyecdysone. Total RNA was prepared immediately following culture and used for Northern analysis. Following hybridization with the $15 \mathrm{a}-1$ probe, Northern blots were hybridized with an 18S rRNA probe.

\section{Results}

\subsection{Selection and sequence of genomic clones}

A 15a-1 genomic clone was isolated from an Ae. aegypti genomic library in the vector EMBL3 
(Stratagene) using the coding region of a 15a-1 cDNA clone as a probe (Lin et al., 1993). The sequence of the $324 \mathrm{bp}$ open reading frame within the $15 \mathrm{a}-1$ genomic clone was $100 \%$ identical to the previously reported $15 \mathrm{a}-$ 1 sequence (Lin et al., 1993). $2.38 \mathrm{~kb}$ of Hind III and Xba I restriction fragments of this clone including the $15 \mathrm{a}-1$ open reading frame and flanking DNA were sequenced (GenBank accession number U91680, Fig. 1). $15 \mathrm{a}-2$ and $15 \mathrm{a}-3$ genomic clones were isolated from an Ae. aegypti genomic library in the vector Lamba DASH (Stratagene). The library was screened using a radiolabeled 200 bp restriction fragment of a 15a-2 partial cDNA clone as a probe (Lin et al., 1993). The 15a-2 genomic clone contained a 291 bp $15 \mathrm{a}-2$ open reading frame that was $100 \%$ identical to the published $15 \mathrm{a}-2$ sequence (Lin et al., 1993). $2.77 \mathrm{~kb}$ of an Eco RI restriction fragment of this clone, including the $15 \mathrm{a}-2$ open reading frame and flanking DNA were sequenced (GenBank accession number U91681, Fig. 1). Genomic clone 15a-3 represents a novel member of the gene family and was isolated by virtue of its cross-hybridization to the $15 \mathrm{a}-2$ probe. $3.02 \mathrm{~kb}$ of Eco RI and Cla I restriction fragments containing the predicted $366 \mathrm{bp} 15 \mathrm{a}-3$ open reading frame and $2.6 \mathrm{~kb}$ of flanking DNA were sequenced (Fig. 1 and GenBank accession number U91682).

The sequence similarity between the open reading frames is shown by a multiple sequence alignment analysis of the predicted peptide sequences (Fig. 2). The percentage of similarity between the three Ae. aegypti vitel- line envelope protein sequences was determined using the GCG Gap program allowing for a gap penalty of 3 , as shown below.

$\begin{array}{lll} & 15 \mathrm{a}-2 & 15 \mathrm{a}-3 \\ 15 \mathrm{a}-1 & 84.3 & 91.7 \\ 15 \mathrm{a}-2 & & 85.3\end{array}$

\subsection{Analysis of the predicted 15a-3 transcriptional unit}

The predicted $15 \mathrm{a}-3$ transcriptional unit contains an 83 base $5^{\prime}$-noncoding region, $366 \mathrm{bp}$ open reading frame and a 137-bp predicted 3 '-untranslated region followed by a poly-A addition signal consensus sequence (AATAAA) (Zarkower and Wickens, 1987). The predicted 15a-3 peptide sequence is shown in Fig. 2. No introns are predicted in the $15 \mathrm{a}-3$ sequence, which is consistent with Ae. aegypti vitelline envelope genes 15a$1,15 \mathrm{a}-2$, and the vitelline envelope genes of $\mathrm{D}$. melanogaster. The first 18 amino acids of the peptide are hydrophobic and are followed by a predicted signal cleavage site (Von Heijne, 1990). This suggests that the $15 \mathrm{a}-3$ protein is synthesized with a signal peptide allowing for secretion. Following signal peptide cleavage, the mature $15 \mathrm{a}-3$ peptide would be $11.1 \mathrm{kDa}$.
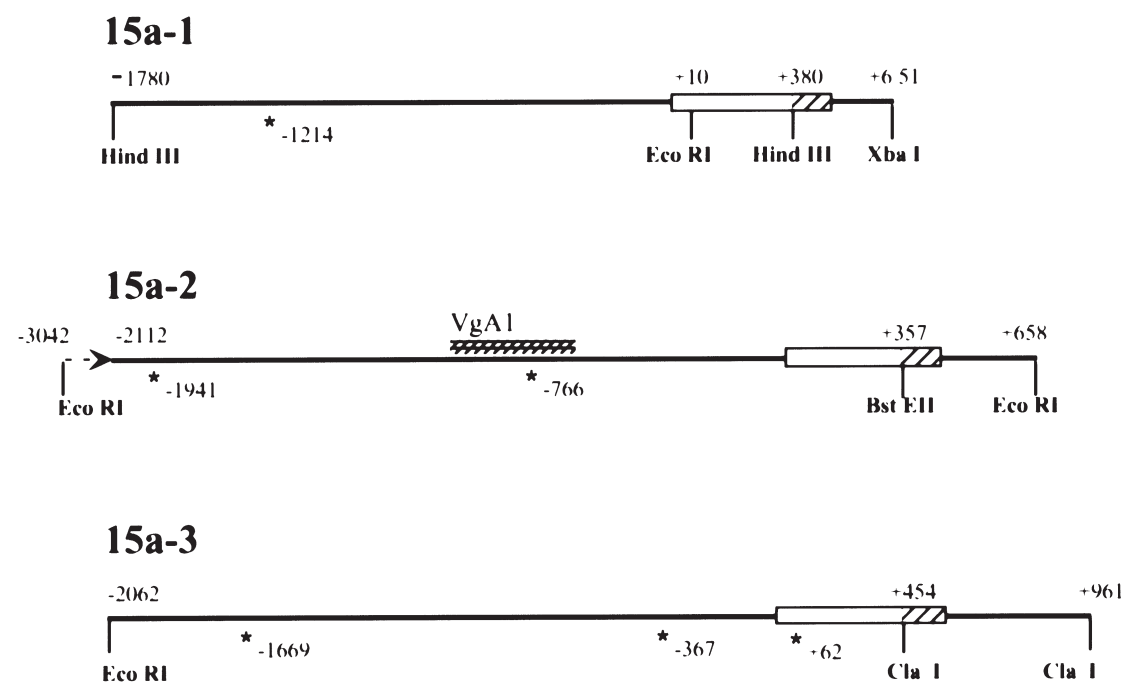

400 bp

Fig. 1. Sequenced regions of three Ae. aegypti vitelline envelope genomic clones, 15a-1, 15a-2 and 15a-3. Open rectangles represent the predicted open reading frames. Hatched rectangles represent the 3 '-untranslated regions that were used as mutually exclusive probes for mRNA expression. Asterisks below indicate potential ecdysone responsive elements, all containing at least 10/12 conserved residues with the D. melanogaster ecdysone responsive element $[\mathrm{PuG}(\mathrm{G} / \mathrm{T}) \mathrm{T}(\mathrm{C} / \mathrm{G}) \mathrm{A}(\mathrm{N}) \mathrm{TG}(\mathrm{C} / \mathrm{A})(\mathrm{C} / \mathrm{A})(\mathrm{C} / \mathrm{t}) \mathrm{Py}]$ (Antoniewski et al., 1993). The hatched bar above $15 \mathrm{a}-2$ (nt -1110 to -750 ) indicates a $360 \mathrm{nt}$ region that is $72 \%$ identical to a sequence upstream of the Ae. aegypti vitellogenin gene VgA1 (Romans et al., 1995). 


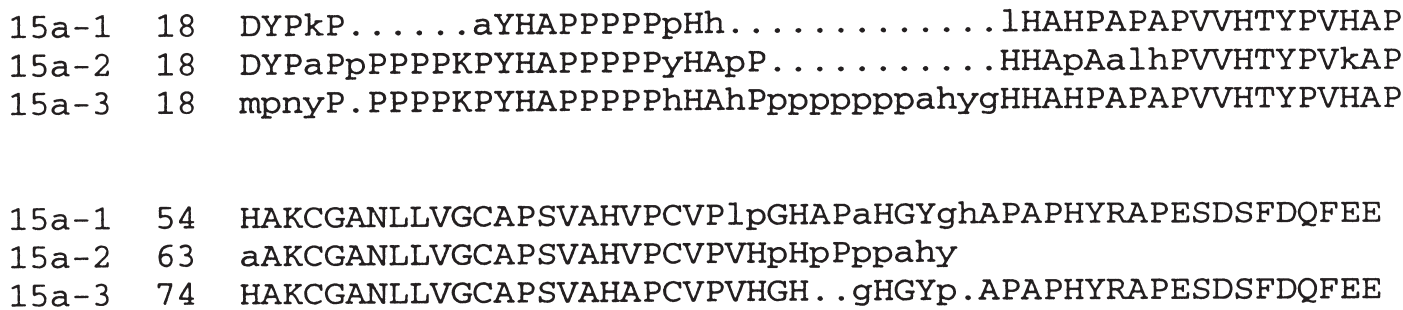

Fig. 2. Multiple sequence alignment of the predicted mature peptide sequences (using CGC Pileup after removal of the predicted signal peptides, gap creation penalty $=3.0$ ) from the $15 \mathrm{a}-1,15 \mathrm{a}-2$ and $15 \mathrm{a}-3$ genes of Ae. aegypti. Residue numbers beginning from the predicted start codons are listed at the beginning of each line. Gaps that improve the alignment are shown as dots. Identities between two or more sequences in the multiple sequence alignment are shown in capital letters.

\subsection{Predicted promoter regions}

A comparative approach was used to predict the promoter elements upstream of the 15a-1, 15a-2 and 15a-3 coding regions (Fig. 3). Sequences consistent with the most frequently occurring arthropod initiator site (Cherbas and Cherbas, 1993) were identified in all three sequences (Fig. 3). Predicted TATA boxes (TATAAA) were identified 27, 26 and $26 \mathrm{bp}$ upstream from the respective predicted initiator sequences. In-frame ATG sequences were identified 65,55 and 76 bp downstream from the respective arthropod initiator sequences. The upstream sequences did not contain regions with similarity to other $D$. melanogaster or mosquito ovary-specific genes when analyzed using the programs BLAST and GAP (Gap penalty = 5.0) (Genetics Computer Group), or Pustell DNA Matrix with a window size of 30 (MacVector, Oxford Molecular Group). A $360 \mathrm{nt}$ region with $72 \%$ identity is located within $1.2 \mathrm{~kb}$ upstream of $15 \mathrm{a}-2$ and the ecdysone-responsive $A e$. aegypti vitellogenin gene, $\mathrm{VgAl}$ (Fig. 4, Romans et al., 1995).

\subsection{Southern blot and RFLP linkage analysis}

Southern blot analysis of EcoRI-digested genomic DNA from single mosquitoes showed that the 15a-1, $15 \mathrm{a}-2$ and $15 \mathrm{a}-3$ clones each hybridized to a single or only a few restriction fragments in a manner expected for single copy genes (Fig. 5). In addition, the restriction fragment patterns were distinct for each clone, indicating that they each hybridized to a separate locus. No evidence for recombination between the $15 \mathrm{a}-3$ locus and the spot locus on chromsome 2 was observed. However, a recombination fraction of 0.043 was observed between the $15 \mathrm{a}-2$ locus and the spot locus, providing further evidence that the clones represent separate loci. Segregation data for 15a-1 was inconclusive. The map position for $15 \mathrm{a}-1$ and multipoint ordering of $15 \mathrm{a}-2$ will be investigated in future studies.

\subsection{Timing of expression}

The relative timing of $15 \mathrm{a}-1,15 \mathrm{a}-2$ and $15 \mathrm{a}-3$ expression following a blood meal was determined by Northern blot analysis (Fig. 6). Due to the highly conserved coding regions of the Ae. aegypti vitelline envelope genes, it was necessary to use mutually exclusive probes corresponding to the $3^{\prime}$-untranslated regions of these genes. These regions ranged from 35 to $45 \%$ identity at the nucleotide level, with no more than seven consecutive identical nucleotides. The probes did not crosshybridize under high stringency hybridization conditions.

Northern blots containing samples of total ovarian RNA prepared at intervals between 0 and $60 \mathrm{~h}$ after a

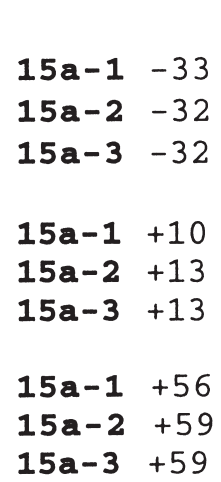

TATA box

Arthropod Initiator

tataaacgcacccagccaagcacttccaatcatcagtcacca. .

tataa . atacccaccgcggatacctcccatcatcagtcaccatc

tataaacccggtggattcggtggattggagcatcagttcgctac

gcaacttgcccaacagtgtactacagtcccaccgaggaattcccat caagcatcaaccagcgtggtacaacagtaatcaacagcaaatcaa acagtatcagtgcagttacatagtatttccaacgacttcggaagga

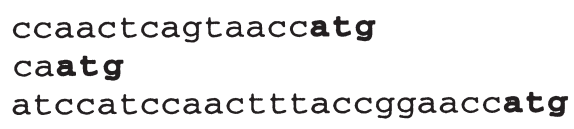

Fig. 3. Promoter regions of 15a-1,15a-2 and 15a-3. Shown in bold are the predicted locations of the TATA box, the arthropod initiator and the translational start site (ATG). Conserved sequences around the initiator are underlined. 


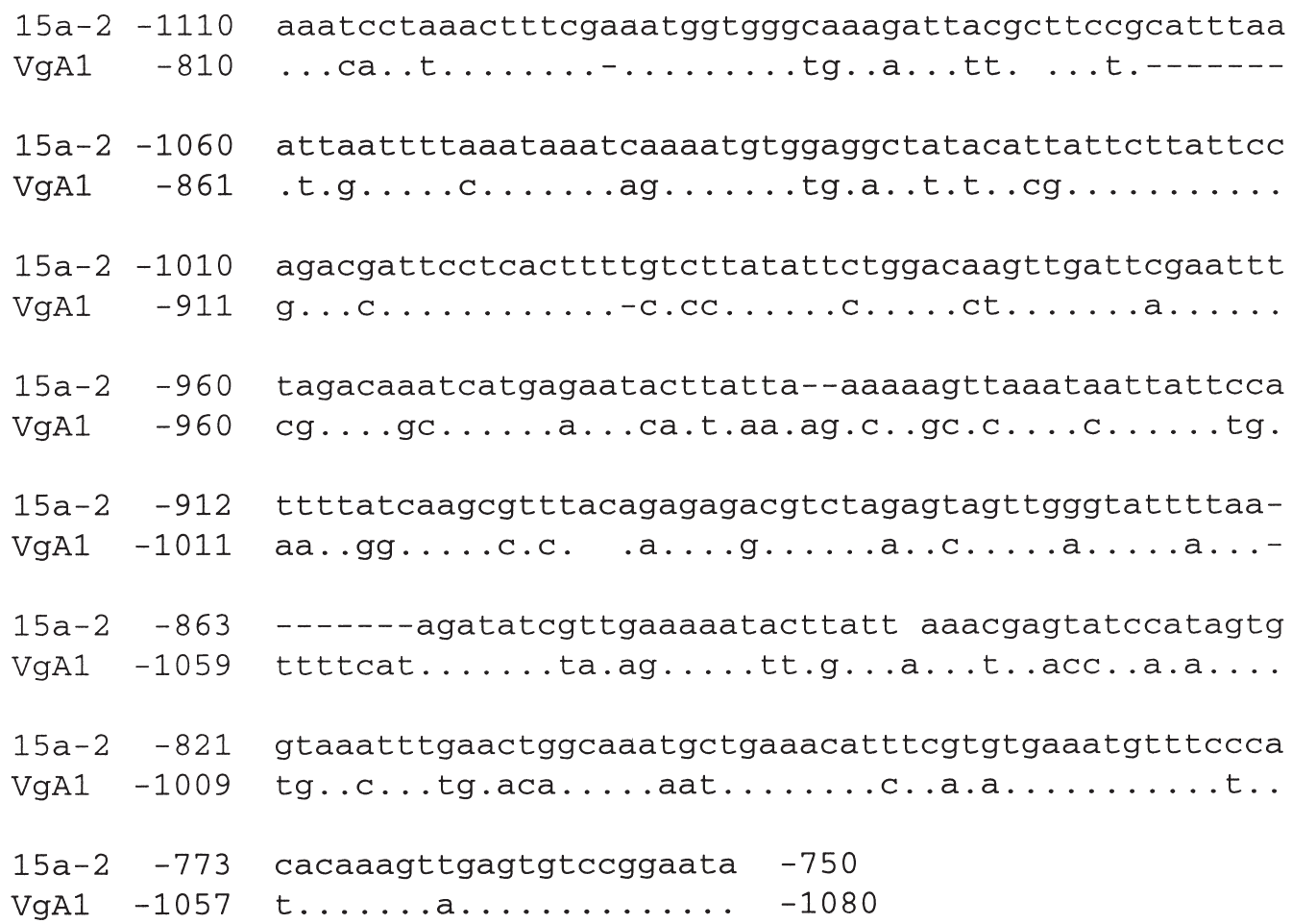

Fig. 4. Similar region contained in both $15 \mathrm{a}-2$ and Ae. aegypti vitellogenin gene VgA1 upstream regions. Using the GCG program Bestfit with a gap creation penalty of 5.0, a $72 \%$ identity was observed within a $360 \mathrm{bp}$ region upstream of the $15 \mathrm{a}-1$ coding region and upstream of the Ae. aegypti vitellogenin gene VgA1 (Romans et al., 1995). The regions were inverted in orientation between the two sequences and started at - 1110 and $-1180 \mathrm{bp}$ upstream of the $15 \mathrm{a}-2$ and $\mathrm{VgA} 1$ coding regions, respectively. Identities are indicated by a period (.). Gaps are indicated by a dash $(-)$.

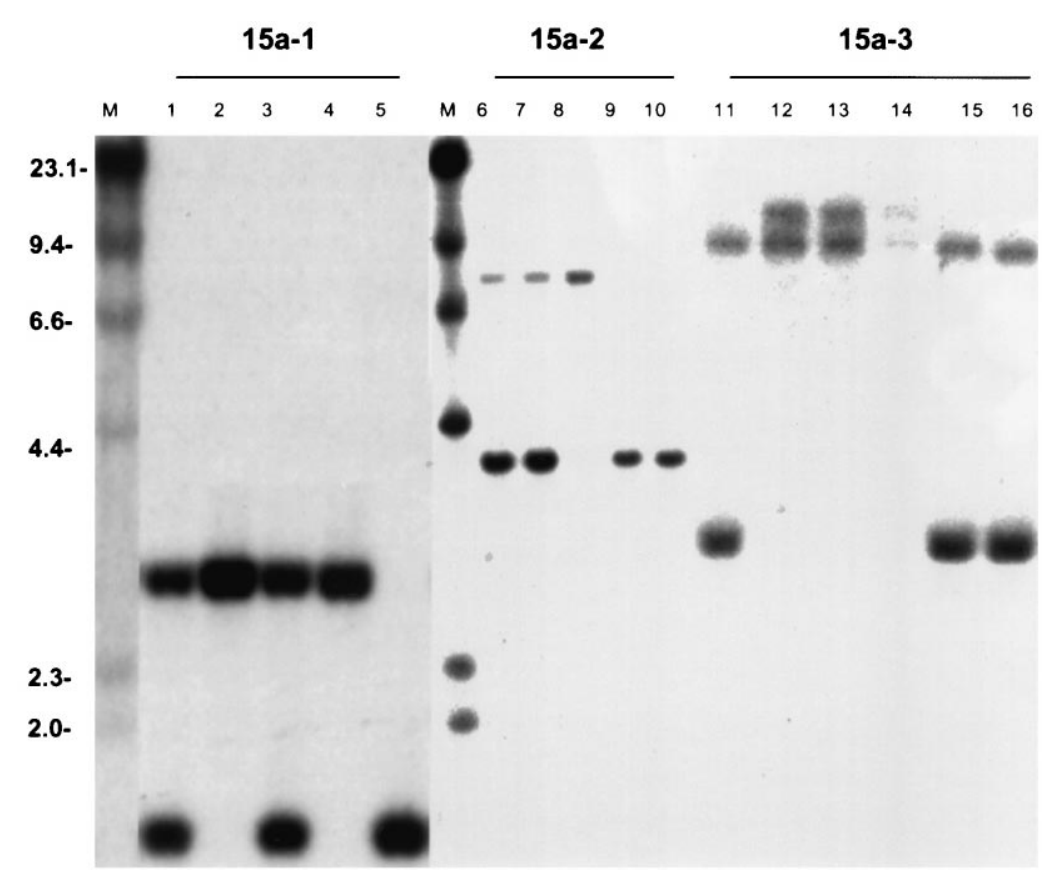

Fig. 5. Southern blot analysis. Composite autoradiogram of genomic southern blots used to screen for 15a-1, 15a-2 and 15a-3 specific restriction length polymorphisms among DNA samples from individual $\mathrm{F}_{2}$ backcrossed Ae. aegypti mosquitoes. $\mathrm{F}_{2}$ backcross populations involved the following pairwise matings: (Formosus strain by RED strain), ( $F_{1}$ backcrossed to RED strain). DNA was digested with EcoRI. M $=$ DNA Marker. Samples according to lane were screened with the following probes: $1-5=15 \mathrm{a}-1 ; 6-10=15 \mathrm{a}-2 ; 11-16=15 \mathrm{a}-3$. Size as determined by HindIII-digested $\lambda$-phage DNA $(\mathrm{kb})$ is presented at the left. 


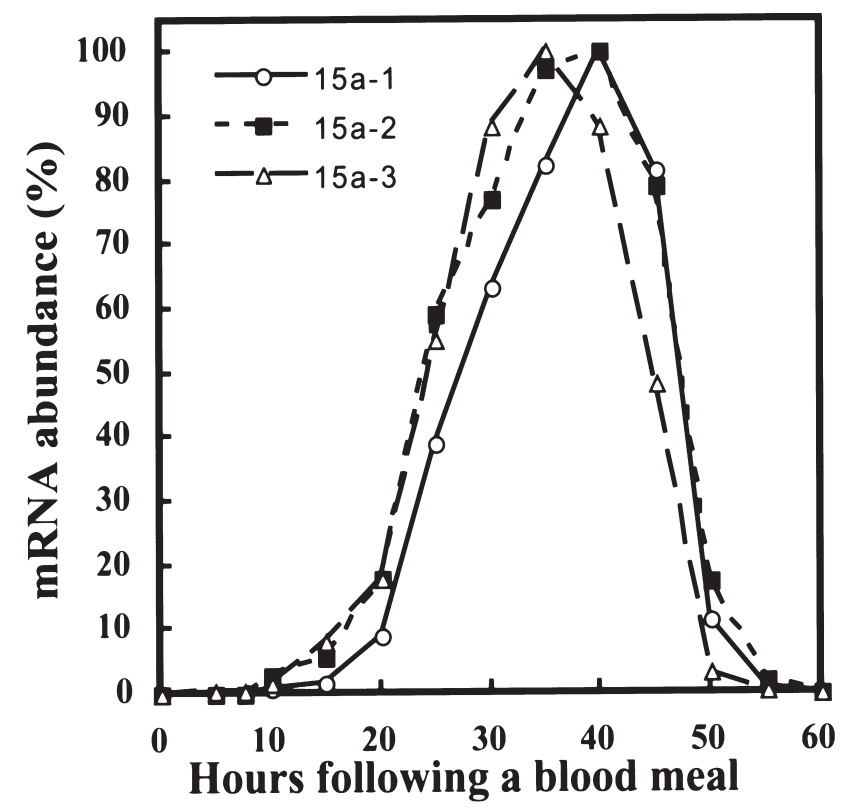

Fig. 6. Time course of $15 a-1,15 a-2$ and $15 a-3$ accumulation after a blood meal. Total RNA was extracted from ovaries at increasing intervals following a blood meal. Approximately $4 \mu \mathrm{g}$ of total RNA were loaded per lane of a northern blot. Since all three transcripts were all detected at the expected size of around 600 nucleotides in comparison to RNA markers (Promega), the northern blot was probed sequentially with the three vitelline envelope and then 18S rRNA probes. Hybridization signals were determined using a Betascope. Values were normalized to the loading control (18S rRNA) values and are expressed as the percentage of the maximal signal for each probe, respectively.

blood meal were sequentially hybridized with mutually exclusive probes for $15 \mathrm{a}-1,15 \mathrm{a}-2,15 \mathrm{a}-3$ and then with the Ae. albopictus 18S RNA probe as a loading control. The highest level of expression of the three genes was observed from 30 to $45 \mathrm{~h}$. By $60 \mathrm{~h}$ expression was not detected. Differences between the relative temporal expression profiles of the three genes were minor (Fig. 6 ). Similar time frames of vitelline envelope gene expression were observed in three separate experiments.

\subsection{Sites of expression}

The sites of 15a-1, 15a-2 and 15a-3 expression at $24 \mathrm{~h}$ after a blood meal were determined by whole-mount in situ hybridization. Mutually exclusive digoxigenin-labeled probes corresponding to the $3^{\prime}$-untranslated regions of the three vitelline envelope genes were used. The relative sites of expression of all three genes at $24 \mathrm{~h}$ after a blood meal are shown in Fig. 7(a-d). The site of $15 \mathrm{a}-2$ expression was strikingly different from $15 \mathrm{a}-1$ and $15 \mathrm{a}-$ 3. Only $15 \mathrm{a}-2$ was expressed in the anterior region, in addition to the remainder of the follicle. Fig. 7(d) shows particularly robust expression of $15 \mathrm{a}-2$ in the rosette cells at the anterior pole of the oocyte. No 15a-3 message was detected in ovaries that were dissected from nonblood fed mosquitoes (not shown). Only a weak signal was detected with the $15 \mathrm{a}-3$ probe in ovaries that were dissected from mosquitoes 10 and $50 \mathrm{~h}$ after a blood meal (not shown). No signal was detected in ovaries dissected from mosquitoes at $24 \mathrm{~h}$ following a blood meal using probes that were prepared by primer extension in the sense orientation as a control.

\subsection{Effect of 20-hydroxyecdysone in vitro}

Ovaries were dissected at $0,2,10$ or $36 \mathrm{~h}$ post-blood meal (PBM). Total RNA was extracted from the ovaries and used for Northern analysis using a 15a-1 coding region probe that cross-hybridizes with $15 \mathrm{a}-2$ and $15 \mathrm{a}-$ 3 . In these ovaries, the message was first detected $2 \mathrm{~h}$ PBM, and was prominent by $10 \mathrm{~h}$ and succeeding times (Table 1, no incubation). Ovaries that were dissected at these time intervals were also incubated for $10 \mathrm{~h}$ in medium containing no hormone (control incubation) or $10^{-5} \mathrm{M} 20$-hydroxyecdysone (ecdysone incubation). For ovaries that were dissected 0,2 and $10 \mathrm{~h}$ PBM, vitelline envelope mRNA abundance was greater following 20hydroxyecdysone incubation than control incubations (Table 1). However, for ovaries dissected at $36 \mathrm{~h}$ PBM, there was no significant difference in vitelline envelope mRNA abundance between 20-hydroxyecdysone and control incubations (Table 1).

\section{Discussion}

\subsection{Vitlelline envelope proteins contain a conserved sequence}

The D. melanogaster vitelline envelope peptide sequences (VM26A1, VM26A2, VM32E and VM34C) contain a conserved region of 38 residues which was described by Scherer et al. (1988) and Gigliotti et al. (1989). In the mosquito sequences, a 46-residue conserved region is also present (Lin et al., 1993). The $D$. melanogaster conserved region overlaps in sequence with the Ae. aegypti conserved region as shown below.

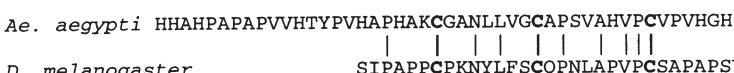

Scherer et al. (1988) suggested that the D. melanogaster conserved region may serve as a site for a protein cross-linking enzyme such as a peroxidase. It is also possible that the conserved regions of the vitelline envelope genes provide a structural conformation that is favorable to the formation of cystine bridges. All of the cysteine residues in the Ae. aegypti and D. melanogaster vitelline envelope sequences are aligned within the conserved region with the exception of a cysteine at position 3 in the mature VM32E peptide (Gigliotti et al., 1989). Evidence for the formation of cysteine bridges between 
a) $15 \mathbf{a}-1$

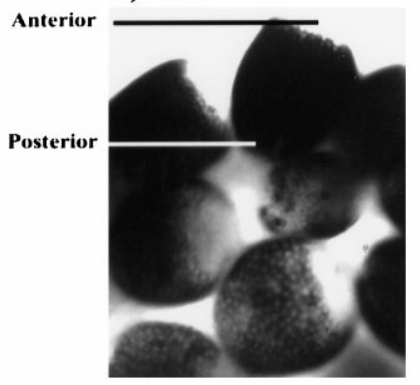

c) $15 \mathrm{a}-3$

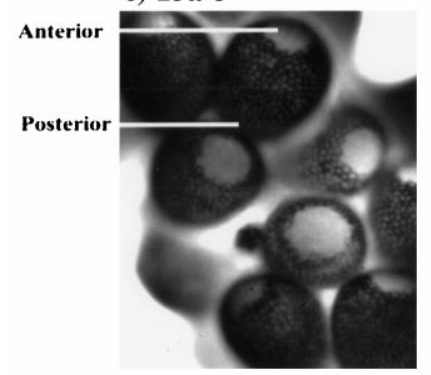

b) $15 \mathrm{a}-2$

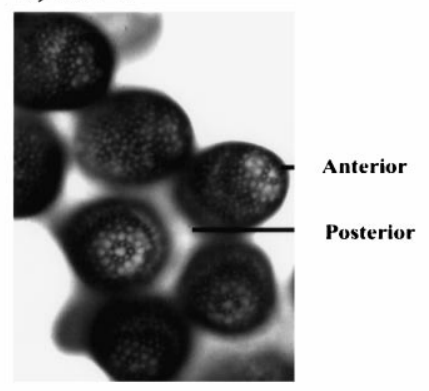

d) $15 \mathbf{a}-2$

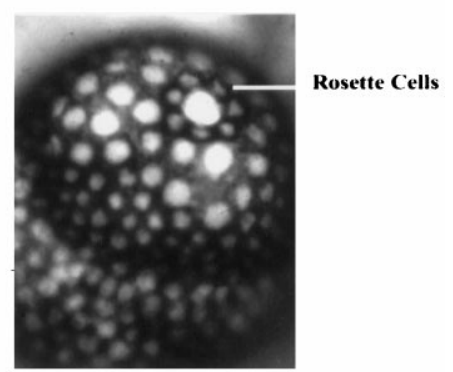

Fig. 7. Site of 15a-1, 15a-2 and 15a-3 expression in ovaries at $24 \mathrm{~h}$ PBM. Whole-mount in situ hybridization was performed using digoxigeninlabeled, mutually exclusive probes corresponding to the respective $3^{\prime}$-untranslated regions. (a) Ovary hybridized with $15 \mathrm{a}-1$ probe $(85 \times$ magnification). (b) Ovary hybridized with $15 \mathrm{a}-2$ probe $(45 \times$ magnification). (c) Ovary hybridized with $15 \mathrm{a}-3$ probe $(55 \times$ magnification). (d) Ovary hybridized with $15 \mathrm{a}-2$ probe enlarged to show the rosette cells at the anterior pole $(225 \times$ magnification $)$.

Table 1

Effect of in vitro incubation with or without 20-hydroxyecdysone on vitelline envelope gene expression in groups of 10 pairs of ovaries dissected at $0,2,10$ and $36 \mathrm{~h}$ after a blood meal. The 0 -h ovaries were dissected immediately after feeding

\begin{tabular}{|c|c|c|c|c|}
\hline Hours after blood meal & No incubation & Control incubation & Ecdysone incubation & 18S RNA \\
\hline 0 & $\begin{array}{l}0 \\
(n=3)\end{array}$ & $\begin{array}{l}0 \\
(n=3)\end{array}$ & $\begin{array}{l}27 \pm 4 \\
(n=3)^{* * \mathrm{a}}, * * \mathrm{~b}\end{array}$ & $\begin{array}{l}525 \pm 26 \\
(n=9)\end{array}$ \\
\hline 2 & $\begin{array}{l}17 \pm 4 \\
(n=3)\end{array}$ & $\begin{array}{l}10 \pm 0.5 \\
(n=4)\end{array}$ & $\begin{array}{l}137 \pm 20 \\
(n=6)^{* * a}, * * b\end{array}$ & $\begin{array}{l}1143 \pm 43 \\
(n=13)\end{array}$ \\
\hline 10 & $\begin{array}{l}262 \pm 39 \\
(n=3)^{* \mathrm{~b}}\end{array}$ & $\begin{array}{l}59 \pm 0.3 \\
(n=3)^{* a}\end{array}$ & $\begin{array}{l}557 \pm 73 \\
(n=3)^{* a}, * * b\end{array}$ & $\begin{array}{l}456 \pm 24 \\
(n=9)\end{array}$ \\
\hline 36 & $\begin{array}{l}1564 \pm 108 \\
(n=3)^{* \mathrm{~b}}\end{array}$ & $\begin{array}{l}955 \pm 157 \\
(n=3)^{* a}\end{array}$ & $\begin{array}{l}773 \pm 87 \\
(n=3)^{* a}\end{array}$ & $\begin{array}{l}198 \pm 16 \\
(n=9)\end{array}$ \\
\hline
\end{tabular}

Ovaries at each time point were treated in three different ways. (1) No incubation: total RNA was extracted from the ovaries immediately after dissection. (2) Control incubation: following dissection, ovaries were incubated for $10 \mathrm{~h}$ in medium without hormone before total RNA was extracted. (3) Ecdysone incubation: following dissection, ovaries were incubated for $10 \mathrm{~h}$ in medium containing $10^{-5} \mathrm{M} 20$-hydroxyecdysone before total RNA was extracted. Samples of RNA were analyzed by northern blots; $12 \mu \mathrm{g}$ was used for the 0,2 and $10 \mathrm{~h}$ time points and $1.2 \mu \mathrm{g}$ was used for the $36 \mathrm{~h}$ time point. The northern blots were probed sequentially with a $15 \mathrm{a}-1$ coding region probe and an $18 \mathrm{~S}$ RNA probe. The value $n$ is the number of replicate groups of ovaries used in each experiment. The 18S RNA column is the average cpm ( \pm standard error) of all of the $18 \mathrm{~S}$ RNA values detected in all of the lanes reported in each row and is included as an indicator of sample variability. The $15 \mathrm{a}-1$ probe cross reacts with the two other Ae. aegypti vitelline envelope genes, resulting in a higher signal than any of the mutually exclusive probes. The results are, therefore, not specific to $15 \mathrm{a}-1$. Values are reported as the mean CPM \pm standard error. *Values are significantly different at $P<0.05$. $* * V a l u e s$ are significantly different at $P<0.01$. "Significantly different from "no incubation" values at the same time. 'Significantly different from "control incubation" values at the same time. Student's $t$-test was used to make comparisons.

D. melanogaster vitelline envelope proteins was provided by Petri et al. (1979), who showed that vitelline envelope proteins are insoluble in $2 \%$ SDS but soluble in a combination of $2 \%$ SDS and $\beta$-merceptoethanol. At this stage of egg development, the chorion is still soluble in $2 \%$ SDS.
The Ae. aegypti vitelline envelope proteins have an unusually high proline content of about $30 \%$. They all contain at least one series of 6-8 consecutive proline residues. 15a-3 contains two stretches of five proline residues and one stretch of eight proline residues. In contrast, there are no more than two consecutive prolines in 
any of the D. melanogaster sequences. Stretches of six or more consecutive proline residues are rare among invertebrate peptides. Unknown properties of $D$. melanogaster vitelline envelope proteins allow this structure to serve as a reservoir for chorion proteins during the early stages of chorion formation (Pasucci et al., 1996). In this context, unique features of the Ae. aegypti vitelline envelope proteins such as highly flexible poly-proline domains may be of similar importance to the molecular architecture of the Ae. aegypti eggshell.

\subsection{Analysis of the upstream regions}

Regulatory elements have been analyzed upstream of three D. melanogaster vitelline envelope genes. Savant and Waring (1989) demonstrated that all of the necessary cis-acting regulatory elements for normal expression were located within $147 \mathrm{bp}$ of the VM26A2 coding region. Jin and Petri (1993) demonstrated that 597 bp of $5^{\prime}$ flanking DNA is sufficient to promote expression of a lacZ reporter gene with the appropriate tissue and stage specificities. Gargiulo et al. (1991) and Cavaliere et al. (1997) showed that the first 465 nucleotides upstream of VM32E confer the appropriate stage and follicle cellspecific expression to a reporter gene. No significant sequence similarity was detected between the mosquito and D. melanogaster upstream sequences.

The upstream regions of the mosquito vitelline envelope genes were analyzed for the presence of $D$. melanogaster ecdysone responsive element (EcRE) consensus sequences. The sequence $[\mathrm{PuG}(\mathrm{G} / \mathrm{T}) \mathrm{T}(\mathrm{C} / \mathrm{G}) \mathrm{A}(\mathrm{N}) \mathrm{TG}(\mathrm{C} / \mathrm{A})(\mathrm{C} / \mathrm{A})(\mathrm{C} / \mathrm{t}) \mathrm{Py}+\mathrm{6}]$ was empirically shown to contain residues that are critical for the binding of $D$. melanogaster ecdysone receptors to oligonucleotides in a gel mobility shift assay (Antoniewski et al., 1993). Sequences with at least 10/12 nucleotide matches and containing all of the critical residues of the D. melanogaster EcRE consensus sequence were identified within $2 \mathrm{~kb}$ of all three open reading frames (Fig. 1) and are shown below.

\begin{tabular}{lll}
\hline Gene & Location & Sequence \\
\hline $15 \mathrm{a}-1$ & -1214 & GGGTCA-cGAAtT \\
$15 \mathrm{a}-2$ & -766 & AGTTGA-TGtCCg \\
$15 \mathrm{a}-3$ & -1669 & GGTgCA-TGAttT \\
& -367 & AGTTCc-cGCAtT \\
\hline
\end{tabular}

An Ae. aegypti ecdysone receptor was cloned by Cho et al. (1995). The nucleotide sequence of the DNA binding domain of the Ae. aegypti ecdysone receptor is $97 \%$ identical to the DNA binding domain of the D. melanogaster ecdysone receptor. Thus, it is likely that $D$. melanogaster EcREs are conserved in Ae. aegypti. Further analysis will be required to determine whether the partial D. melanogaster EcRE consensus sequences that were found upstream of the coding regions actually bind to Ae. aegypti ecdysone receptors.

A region of similarity was found between the $15 \mathrm{a}-2$ upstream sequence and that of an Ae. aegypti vitellogenin gene, VgA1 (Romans et al., 1995). This 360 bp region is $810 \mathrm{bp}$ upstream of the $15 \mathrm{a}-2$ transcriptional start site and is $72 \%$ identical to a region $750 \mathrm{bp}$ upstream of the $\mathrm{VgA} 1$ transcriptional start site (Fig. 4). The region has been shown to be a repetitive element of an unknown class (Zhijian Tu, personal communication), and is indicated by a hatched bar in Fig. 1. The timing of $\mathrm{VgA} 1$ expression is similar to $15 \mathrm{a}-2$ expression. However, the site of $\mathrm{VgA} 1$ expression is the fat body rather than the ovaries (Gemmill et al., 1986). The 15a-2 upstream region also contains a Wuneng miniature inverted-repeat transposable element (MITE)-like sequence between 682 and $740 \mathrm{nt}$ upstream of the transcriptional start site (Tu, 1997).

\subsection{Patterns of $m R N A$ expression}

The temporal expression profiles of all three vitelline envelope genes were very similar (Fig. 6). This suggests that these genes share a common regulatory mechanism with respect to the timing of expression. In contrast, the spatial expression patterns of these genes were not coordinate (Fig. 7). All three genes were expressed in the middle and posterior regions of the follicle. This observation is consistent with results of Lin et al. (1993) who performed in situ hybridization with paraffin-sectioned Ae. aegypti ovaries following a blood meal using a radiolabeled $15 \mathrm{a}-1$ probe. However, only $15 \mathrm{a}-2$ was expressed in the anterior region of the follicle where the nurse cells are located (Fig. 7(d)). Lin et al. (1993) did not observe $15 \mathrm{a}-1$ expression in this region. At least in the anterior region of the follicle, the genes did not appear to share a common regulatory mechanism with respect to their spatial expression.

Nicholson (1921) found that the An. maculipennis micropylar apparatus was formed by a specialized group of follicle cells (rosette-cells), which are located in the anterior region of the follicle. In D. melanogaster, an inner layer of the micropylar apparatus is formed by the border cells of the follicular epithelium (Margaritis, 1985). Jin and Petri (1993) observed the expression of a reporter gene in the border cells when the reporter gene was linked to DNA sequences upstream of a vitelline envelope gene (VM26A1). We suggest that 15a-2 expression in the rosette cells, adjacent to the nurse cells, may contribute to the Ae. aegypti micropyle.

\subsection{Ecdysone regulation of vitelline gene expression}

The vitelline envelope first appears 8 to $10 \mathrm{~h}$ PBM as discreet protein droplets called "vitelline bodies" or 
"plaques" (Mathew and Rai, 1975; Raikhel and Lea, 1991). At approximately $8 \mathrm{~h}$ PBM, the 20 -hydroxyecdysone titer of the female mosquito rises sharply and then peaks between 16 and $20 \mathrm{~h}$ PBM (Greenplate et al., 1985; Racioppi et al., 1986). Raikhel and Lea (1982, 1991) have shown that the secretion of the vitelline envelope proteins from the follicular epithelium can be induced by injections of 20-hydroxyecdysone into decapitated females that were given blood by enema. Lin et al. (1993) demonstrated that vitelline envelope gene expression was induced in ovaries of blood-fed and decapitated females in response to an injection of $1 \mu \mathrm{g}$ of 20-hydroxyecdysone in saline. Vitelline envelope gene expression was detected in ovaries that were dissected from non-blood fed mosquitoes and cultured for $24 \mathrm{~h}$ in medium containing $10^{-5} \mathrm{M} 20$-hydroxyecdysone. No expression was detected in ovaries that were cultured in medium that did not contain 20-hydroxyecdysone (Lin et al., 1993).

Expression of the vitelline envelope mRNA was not detectable immediately after a blood meal, but rose between 2 and $10 \mathrm{~h}$ after a blood meal (Fig. 6, Table 1). Expression was greater in ovaries that were dissected from blood-fed females at 0 to $10 \mathrm{~h} \mathrm{PBM}$, and then incubated with 20-hydroxyecdysone (Table 1). In contrast, expression was not greater in ovaries that were dissected at $36 \mathrm{~h} \mathrm{PBM}$ and incubated in 20-hydroxyecdysone (Table 1). During the course of egg development, it is likely that the follicular epithelium changes in its responsiveness to 20-hydroxyecdysone. The regulation of vitelline envelope gene expression may be modulated by these changes in responsiveness. Similar results were obtained by Bohm et al. (1978) for the expression of vitellogenin genes in response to 20-hydroxyecdysone.

\section{Acknowledgements}

This work was supported by NIH grant (HD24869) to H.H. Hagedorn and A.M. Fallon, and by the John D. and Catherine T. MacArthur Foundation. The authors thank Dr Anthony James at the University of California, Irvine, for the Lambda-Dash Ae. aegypti genomic library, and Skip Vaught at the University of Arizona Division of Biotechnology for sequencing the majority of the DNA reported in this manuscript.

\section{References}

Anderson, W.A., Spielman, A., 1971. Permeability of the ovarian follicle of Aedes aegypti mosquitoes. J. Cell Biol. 50, 201-221.

Anderson, W.A., Spielman, A., 1973. Incorporation of RNA and protein precursors by ovarian follicles of Aedes aegypti mosquitoes. J. Submicr. Cytol. 5, 181-198.

Antoniewski, C., Laval, M., Lepesant, J.-A., 1993. Structural features critical to the activity of an ecdysone receptor binding site. Insect Biochem. Mol. Biol. 23, 105-114.

Barillas-Mury, C., Wells, M.A., 1993. Cloning and sequencing of the blood meal-induced late trypsin gene from the mosquito Aedes aegypti and characterization of the upstream regulatory region. Insect Mol. Biol. 2, 7-12.

Bohm, M.K., Behan, M., Hagedorn, H.H., 1978. Termination of vitellogenin synthesis by mosquito fat body, a programmed response to ecdysone. Physiol. Entomol. 3, 17-25.

Cavaliere, V., Spano, S., Andrenacci, D., Cortesi, L., Gargiulo, G., 1997. Regulatory elements in the promoter of the vitelline membrane gene VM32E of Drosophila melanogaster direct gene expression in distinct domains of the follicular epithelium. Mol. Gen. Genetics. 254, 231-237.

Cherbas, L., Cherbas, P., 1993. The arthropod initiator: the capsite consensus plays an important role in transcription. Insect Biochem. Mol. Biol. 23, 81-90.

Cho, W.-L., Kapitskaya, M.Z., Raikhel, A.S., 1995. Mosquito ecdysteriod receptor: analysis of the cDNA and expression during vitellogenesis. Insect Biochem. Mol. Biol. 25, 19-27.

Christensen, B.M., Sutherland, D.R., 1984. Brugia pahangi: exheathment and midgut penetration in Aedes aegypti. Am. Micro. Soc. 103, 423-433.

Devereaux, J., Haeberli, P., Smithies, O., 1984. A comprehensive set of sequence analysis programs for the VAX. Nucleic Acids Res. 12, 387-395.

Edwards, M.J., 1996. The vitelline membranes of Aedes aegypti and Drosophila melanogaster: a comparative review. Inv. Reprod. and Develop. 30, 255-264.

Feinberg, A.P., Vogelstein, B., 1983. A technique for radiolabeling DNA restriction fragments to high specificity. Anal. Biochem. 132, 6-13.

Gargiulo, G., Gigliotti, S., Malva, C., Graziani, F., 1991. Cellular specificity and regulation of Drosophila melanogaster vitelline membrane protein $32 \mathrm{E}$ gene in the follicular epithelium: identification of cis-acting elements. Mech. Develop. 35, 193-203.

Gemmill, R.M., Hamblin, M., Glaser, R.L., Racioppi, J.V., Marx, J.L., White, B.N., Calvo, J.M., Wolfner, M.F., Hagedorn, H.H., 1986. Isolation of mosquito vitellogenin genes and induction of expression by 20-hydroxyecdysone. Insect Biochem. 16, 761-774.

Gigliotti, S., Graziani, F., DePonti, L., Rafti, F., Manzi, A., Lavorgna, G., Gargiulo, G., Malva, C., 1989. Sex-tissue and stage-specific expression of a vitelline membrane protein gene from region 32 of the second chromosome of Drosophila melanogaster. Dev. Genet. $10,33-41$.

Greenplate, J.T., Glaser, R.L., Hagedorn, H.H., 1985. The role of factors from the head in the regulation of egg development in the mosquito Aedes aegypti. J. Insect Physiol. 31, 323-329.

Hagedorn, H.H., O'Connor, J.P., Fuchs, M.S., Sage, B., Schlaeger, D.A., Bohm, M.K., 1975. The ovary as a source of alpha-ecdysone in an adult mosquito. Proc. Nat. Acad. Sci. U.S.A. 72, 3255-3259.

Jin, J., Petri, W.H., 1993. Developmental control elements in the promoter of a Drosophila vitelline membrane gene. Dev. Biol. 156, 557-565.

Lander, E.S., Green, P., Abrahamson, J., Barlow, A., Daly, M., Lincoln, S., Newburg, L., 1987. MAPMAKER: an interactive computer package for constructing primary genetic linkage maps of experimental and natural populations. Genomics 1, 174-181.

Lin, Y., Hamblin, M.T., Edwards, M.J., Barillas-Mury, C., Kanost, M.R., Knipple, D.C., Wolfner, M.F., Hagedorn, H.H., 1993. Structure, expression, and hormonal control of genes from the mosquito, Aedes aegypti, which encode proteins similar to the vitelline membrane proteins of Drosophila melanogaster. Dev. Biol. 155, 558568.

Margaritis, L.H., 1985. Structure and physiology of the eggshell. In: Kerkut, G.A., Gilbert, L.I. (Eds.), Comprehensive Insect Physi- 
ology, Biochemistry and Pharmacology, Vol. 1. Pergamon Press, Oxford, pp. 153-230.

Mathew, G., Rai, K.S., 1975. Structure and formation of egg membranes in Aedes aegypti (L.)(Diptera: Culicidae). Int. J. Insect Morphol. Embryol. 4, 369-380.

Nicholson, A.J., 1921. The development of the ovary and ovarian egg of a mosquito, Anopheles maculipennis, Mieg. Quart. J. Micr. Sci. $65,435-452$.

Noriega, F.G., Wells, M.A., 1993. A comparison of three methods for isolating RNA from mosquitoes. Insect Mol. Biol. 2, 21-24.

Pasucci, T., Perrino, J., Mahowald, A.P., Waring, G.L., 1996. Eggshell assembly in Drosophila: processing and localization of vitelline membrane and chorion proteins. Dev. Biol. 177, 590-598.

Petri, W.H., Mindrinos, M.N., Lombard, M.F., 1979. Independence of vitelline membrane and chorion cross linking in the Drosophila melanogaster eggshell. J. Cell Biol. 83, 23a.

Powell, J.R., Hollander, A.L., Fuchs, M.S., 1988. Development of the Aedes aegypti chorion: proteins and ultrastructure. Int. J. Invertebr. Rep. Dev. 13, 39-54.

Racioppi, J.V., Gemmill, R.M., Kogan, P.K., Calvo, J.M., Hagedorn, H.H., 1986. Expression and regulation of vitellogenin messenger RNA in the mosquito, Aedes aegypti. Insect Biochem. 16, 255262.

Raikhel, A.S., Lea, A.O., 1982. Abnormal vitelline envelope induced by unphysiological doses of ecdysterone in Aedes aegypti. Physiol. Entomol. 7, 55-64.

Raikhel, A.S., Lea, A.O., 1991. Control of follicular epithelium development and vitelline envelope formation in the mosquito; role of 20-hydroxyecdysone. Tiss. Cell 23, 577-591.

Regier, J.C., Kafatos, F.C., 1985. Molecular aspects of chorion formation. In: Kerkut, G.A., Gilbert, L.I. Comprehensive Insect Physiology, Biochemistry and Pharmacology Vol. 1. Pergamon Press, Oxford, pp. 113-151.

Romans, P., Tu, Z., Ke, Z., Hagedorn, H.H., 1995. Analysis of a vitellogenin gene of the mosquito, Aedes aegypti and comparisons to vitellogenins from other organisms. Insect Biochem. Mol. Biol. 25, 939-958.
Sambrook, J., Fritsch, E., Maniatis, T., 1989. Molecular Cloning: A Laboratory Manual, 2nd ed. Cold Spring Harbor Laboratory, New York.

Savant, S.S., Waring, G.L., 1989. Molecular analysis and rescue of a vitelline membrane mutant in Drosophila melanogaster. Dev. Biol. $135,43-52$.

Scherer, L.J., Harris, D.H., Petri, W.H., 1988. Drosophila melanogaster vitelline membrane genes contain an 114 base pair region of highly conserved coding sequence. Dev. Biol. 130, 186-788.

Scherer, L.J., Harris, D.H., White, M.K., Steel, L.F., Jin, J., Petri, W.H., 1993. Comparative analysis of the sequence and structure of two Drosophila melanogaster genes encoding vitelline membrane proteins. Gene 136, 121-127.

Severson, D.W., 1997. RFLP analysis of insect genomes. In: Crampton, J.M., Beard C.B., Louis C. (Eds.), The Molecular Biology of Insect Disease Vectors: A Methods Manual. Chapman and Hall, London, pp. 309-320.

Shapiro, J.P., Hagedorn, H.H., 1982. Juvenile hormone and the development of ovarian responsiveness to a brain hormone in the mosquito Aedes aegypti. Gen. Comp. Endocr. 46, 176-183.

Tautz, D., Pfeifle, C., 1989. A non-radioactive in situ hybridization method for the localization of specific RNAs in Drosophila embryos reveals a translational control of the segmentation gene hunchback. Chromosoma 98, 81-85.

Tu, Z., 1997. Three novel families of miniature inverted-repeat transposable elements that are associated with genes of the yellow fever mosquito, Aedes aegypti. Proc. Nat. Acad. Sci. U.S.A. 94, 74757480 .

Von Heijne, G., 1990. The signal peptide. J. Membr. Biol. 115, 195-201.

Yonge, C., Hagedorn, H.H., 1977. Dynamics of vitellogenin uptake in Aedes aegypti as demonstrated by trypan blue. J. Insect Physiol. 23, 1199-1203.

Zarkower, D., Wickens, M., 1987. Formation of mRNA 3'-termini: stability and dissociation of a complex involving the AAUAAA sequence. EMBO J. 6, 177-186. 